\title{
Detection of Chlamydia trachomatis inclusions in McCoy and HeLa-229 cells: an alternative staining technique using toluidine blue
}

\author{
NOORIA RS MOHAMMED, IRENE B HILLARY \\ From the Department of Medical Microbiology, University College Dublin, Ireland
}

SUMMARY Toluidine blue staining was used to detect Chlamydia trachomatis inclusions in both McCoy and HeLa-229 cells from clinical specimens. This method was more sensitive than iodine staining for detecting $C$ trachomatis inclusions in both McCoy and HeLa-229 cells and also more $\infty_{N}^{\infty}$ sensitive than Giemsa staining for detecting chlamydial inclusions in HeLa-229 cells. While its $ᄋ$ sensitivity for detection of chlamydial inclusions in McCoy cells is equal to that of Giemsa $\rightarrow$ staining, toluidine blue staining is easier and faster to perform.

Different staining methods have been used to detect chlamydial inclusions in cell cultures. Giemsa staining followed by dark ground microscopy has been the most commonly used technique. The glycogen matrix of Chlamydia trachomatis inclusions can be detected using various stains-for example, iodine' carmine ${ }^{2}$ and periodic acid Schiff. ${ }^{3}$ Iodine staining combined with bright field microscopy is probably the simplest of all staining techniques for detecting $C$ trachomatis inclusions, but compared with Giemsa and carmine it is less sensitive. ${ }^{4}$ Periodic acid Schiff stain is useful in that inclusions are detectable by both bright and dark field microscopy, but the actual staining technique is quite complex, as is that for carmine. ${ }^{5}$ Methylene blue stain combined with dark field microscopy is said to be useful for the diagnosis of infection caused by the enzootic ovine abortion strain of $C$ psittaci. ${ }^{6}$ But it offers no advantage over Giemsa or iodine stains for the detection of $C$ trachomatis inclusions. ${ }^{5}$

Immunofluorescent staining ${ }^{7}$ seems to be both fast and sensitive but it requires the use of expensive reagents. Recently, a methyl green-neutral red staining technique has been found to be highly sensitive for detecting $C$ psittaci inclusions combined with bright field microscopy. ${ }^{8}$ It is as sensitive as Giemsa staining combined with dark field microscopy for detecting $C$ trachomatis inclusions.

We report a simple, fast technique for detecting $C$ trachomatis inclusions using toluidine blue, effective with both bright and dark field microscopy. We have compared its sensitivity with that of Giemsa and iodine stains for detecting $C$ trachomatis inclusionso from clinical specimens using McCoy and HeLa-229. cells.

\section{Material and methods}

\section{CLINICAL SPECIMENS}

Cervical, urethral, and eye swabs received at the $\overrightarrow{\vec{O}}$ Virus Reference Laboratory, Department of Medi- 3 cal Microbiology, University College Dublin, which were positive for chlamydiae by Giemsa staining. were used in this study.

Fresh swabs from patients were immersed in:bijoux bottles containing $2 \mathrm{ml}$ of transport medium consisting of medium 199 supplemented with $10 \%$ fetal calf serum, $10 \%$ sorbitol, $200 \mu \mathrm{g} / \mathrm{ml}$ streptomycin, and 100 units $/ \mathrm{ml}$ mycostatin, adjusted too pH 7.2-7.4 with $4.4 \%$ sodium bicarbonate. AlP specimens were stored at $-70^{\circ} \mathrm{C}$ on arrival at theo laboratory until inoculated.

\section{CELL CULTURES}

The preparation of cycloheximide-treated McCoy coverslip monolayer cultures and isolation proce- $-\sigma$ dures were as described by Davies et $\mathbf{l}^{9}$ except thak vials were seeded with $2 \mathrm{ml}$ of cell suspension at ac concentration of $3 \times 10^{5}$ cells per $\mathrm{ml}$ and allowed tos form a monolayer.

For preparation of HeLa-229 monolayers $2 \mathrm{ml}$ of cell suspension containing $3 \times 10^{5}$ cells per $\mathrm{ml}$ waș dispensed into flat bottomed vials containing $10 \mathrm{~mm}$ diameter coverslips. The seeded vials were incu- $\frac{}{\sigma}$ bated at $36^{\circ} \mathrm{C}$ for $24 \mathrm{~h}$. Cell monolayers which 
Table 1 Chlamydia trachomatis inclusion counts in McCoy cells

\begin{tabular}{|c|c|c|c|}
\hline \multirow{2}{*}{$\begin{array}{l}\text { Clinical } \\
\text { specimens }\end{array}$} & \multicolumn{3}{|c|}{${ }^{*}$ Mean inclusion count $(I c)$} \\
\hline & Giemsa & Iodine & Toluidine blue \\
\hline Cervix & 244 & 76 & 238 \\
\hline , & 1602 & 389 & 1572 \\
\hline , & 26 & 7 & 29 \\
\hline " & 42 & 12 & 42 \\
\hline$"$ & 2783 & 900 & 2700 \\
\hline ” & 1115 & 269 & 1104 \\
\hline Urethral & 14 & 4 & 15 \\
\hline Urethral & 10 & 3 & 10 \\
\hline ", & 5577 & 1138 & 5466 \\
\hline$"$ & 5 & 0 & 5 \\
\hline$"$ & 980 & 222 & 980 \\
\hline & 7038 & 2163 & 8652 \\
\hline Eye" & 733 & 138 & 704 \\
\hline , & 18 & 4 & 17 \\
\hline$"$ & 368 & 69 & 335 \\
\hline
\end{tabular}

*Mean number counted on two coverslips.

Ic = Inclusion count in $10 \mathrm{~mm}$ coverslip cultures.

formed on the coverslips were then treated with cycloheximide in fresh growth medium to give a final concentration of $1 \mu \mathrm{g} / \mathrm{ml}$ immediately before inoculation. Clinical specimens were homogenised on a Vortex mixer before inoculation. Six monolayer cultures of each cell line were used for each specimen and the inoculum volume was $0.2 \mathrm{ml}$. Inoculated cultures were centrifuged at $3500 \mathrm{rpm}$ (MSE Super-Medium) for $1 \mathrm{~h}$ and then incubated at $36^{\circ} \mathrm{C}$ in an atmosphere of $5 \% \mathrm{CO}_{2}$. After $48 \mathrm{~h}$, two cultures of each type were stained by Giemsa stain, two by iodine, and two by toluidine blue.

The procedure used for counting inclusions was as described by Johnson and Hobson. ${ }^{10}$

\section{STAINING TECHNIQUES}

Toluidine blue monolayer cultures infected with chlamydiae were fixed in absolute methanol for 5 min. This was replaced by toluidine blue (BDH Chemicals Ltd) solution ( $5 \mathrm{~g} / \mathrm{l})$, and cultures were stained for 5-10 min. The stain was then poured off, and the cultures were washed once in tap water, and then in tap water acidified to $\mathrm{pH} 2.5$ with $\mathrm{H}_{2} \mathrm{SO}_{4}$, followed by another wash in tap water. The cover-. slip cultures were then removed from the vials, dehydrated in acetone and then cleared in xylene, and mounted on microscope slides with DPX. Examination of the cultures by bright field microscopy showed that cytoplasm was stained pale blue while nuclei stained slightly darker blue. The chlamydial inclusions stained a deep blue colour. With dark field microscopy the cytoplasm and cell nuclei appeared greenish brown while chlamydial inclusions appeared auto-fluorescing bright yellow.

Giemsa and iodine staining techniques were carried out according to Johnson. ${ }^{2}$

\section{Results}

- The results with each of the three staining techniques were compared by counting the number of inclusions in $10 \mathrm{~mm}$ coverslip monolayer cultures by dark field microscopy.

Table 1 summarises the results of inclusion counts detected in clinical specimens by Giemsa, iodine, and toluidine blue staining techniques in McCoy cells. At least three times more chlamydial inclusions were detected with toluidine blue than with iodine staining. There was no significant difference between the numbers of inclusion counts using toluidine blue and Giemsa stains from clinical specimens $(p>0.05)$, but the inclusions were more defined with toluidine blue.

Table 2 summarises the results of inclusion counts detected in clinical specimens with Giemsa, iodine, and toluidine blue staining in HeLa-229 cells. Three to seven times more inclusions were detected with toluidine blue than with iodine staining and one and a half to three times more inclusions were detected with toluidine blue than with Giemsa staining, the difference being significant $(p<0 \cdot 01)$.

\section{Discussion}

No clearly superior cytological staining method has been described for screening inoculated tissue cultures for chlamydial isolation. The options are largely limited to iodine, Giemsa, and fluorescence techniques. It appears that there may be some difference depending on cell type. ${ }^{11}$

The results of this study show that toluidine blue staining was more sensitive than one of the conventionally used stains - that is, iodine-for detecting $C$ 
Table 2 Chlamydia trachomatis inclusion counts in HeLa-229 cells

\begin{tabular}{|c|c|c|c|}
\hline \multirow{2}{*}{$\begin{array}{l}\text { Clinical } \\
\text { specimens }\end{array}$} & \multicolumn{3}{|c|}{${ }^{*}$ Mean inclusion count $($ Ic) } \\
\hline & Giemsa & Iodine & Toluidine blue \\
\hline Cervix & 3009 & 1312 & 4952 \\
\hline , & 16 & 8 & 29 \\
\hline$"$ & 121 & 45 & 314 \\
\hline$"$, & 8 & 3 & 17 \\
\hline ", & 1093 & 478 & 1672 \\
\hline$"$ & 105 & 39 & 241 \\
\hline Urethral & 2 & 0 & 4 \\
\hline Uretnral & 1398 & 557 & 2322 \\
\hline 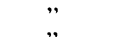 & 91 & 52 & 282 \\
\hline$"$ & 1102 & 501 & 1982 \\
\hline$"$ & 56 & 19 & 93 \\
\hline$"$ & 4108 & 1260 & 6500 \\
\hline Eye" & 800 & $\begin{array}{r}0 \\
265\end{array}$ & $\begin{array}{r}3 \\
1224\end{array}$ \\
\hline, & 5 & 3 & 13 \\
\hline
\end{tabular}

trachomatis in both McCoy and HeLa-229 cells. HeLa cells, however, do not lend themselves to routine use of the iodine staining technique because they occasionally have light iodine staining material in the cytoplasmic background;" also iodine staining is rather limited by being positive for a relatively short time within the developmental cycle of the inclusion." Johnson $e^{\prime} a^{4}$ found that staining with iodine resulted in appreciable underestimation of the number of inclusions present even after incuba-

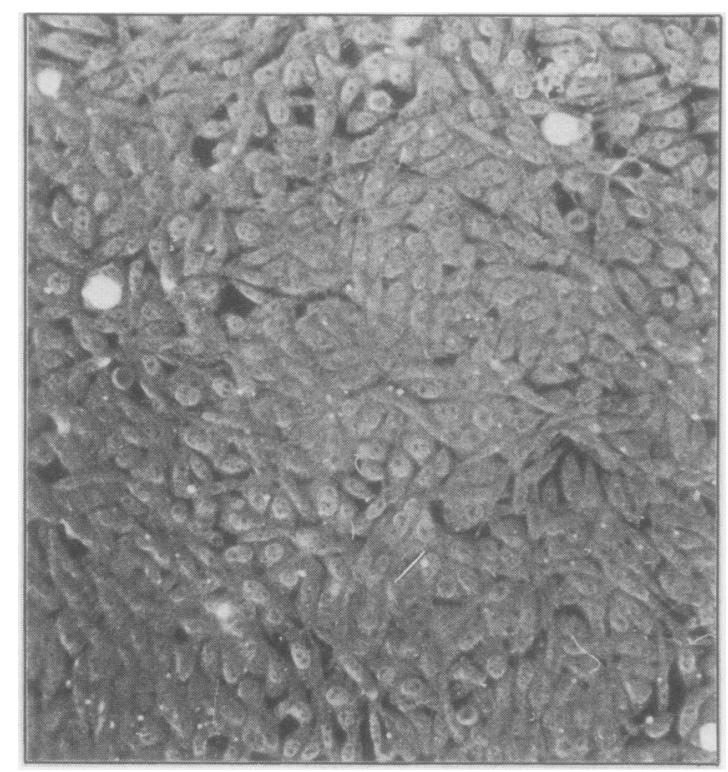

Chlamydia trachomatis inclusions in McCoy cells stained with toluidine blue under dark field microscopy. Original magnification $\times 200$. tion for $48 \mathrm{~h}$. This may be because the amount of glycogen in the inclusions and therefore the effectiveness of a glycogen stain varies during the chlamydial growth cycle. ${ }^{12}$

Toluidine blue staining was more sensitive than ${ }^{+}$ Giemsa staining for detecting $C$ trachomatis in HeLa-229 cells, while both stains were equally sen-క sitive for detecting this organism in McCoy cells Toluidine blue staining, however, has the following advantages over Giemsa staining: firstly, it is more sensitive for detecting inclusions in HeLa-229 cells $; \overrightarrow{\vec{P}}$ secondly, the bright yellow inclusions are more easily seen against the dull matt greenish brown background under dark field microscopy (see Figure) thirdly, toluidine blue is a stable solution which can be stored at room temperature for months, while. Giemsa stain must be prepared freshly for each batch of cultures; and, finally, toluidine blue staining can be performed in 5-10 min whereas the Giemsa? technique takes $30 \mathrm{~min}$. These factors are clearly advantageous in routine screening of large numbers of clinical specimens in a busy laboratory.

We acknowledge the help of Seamus Dooley and Gerardine McQuoid in the preparation of this paper.

References

' Gordon FB, Quan AL. Occurrence of glycogen in inclusions of the Psittacosis-lymphogranuloma venereum agent. J Infect Dis 1965;115: 186-96.

2 Johnson FWA. A comparison of staining techniques for demons trating group A chlamydia in tissue culture. Med Lab Techno 1975;32:233-8.

${ }^{3}$ Mallinson H, Sikotra S, Arga OP. Cultural method for large scale screening for chlamydia trachomatis genital infection. $\mathcal{E}$ Clin Pathol 1981;34:712-8.

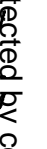


4 Johnson FWA, Hobson D, Rees E, Tait IA. Quantitative aspects of the growth of Chlamydia trachomatis in diagnostic tissue culture procedures. In: Hobson D, Holmes KK, eds. Nongonococcal urethritis and related infections. Washington DC: American Society for Microbiology, 1977:309-13.

s Evans RT, Woodland RM. Detection of chlamydia by isolation and direct examination. Br Med Bull 1983;39:181-6.

- Johnson FWA, Chancerelle LYJ, Hobson D. An improved method for demonstrating the growth of chlamydia in tissue culture. Med Lab Sci 1978;35:67-74.

' Woodland RM, El-Sheikh H, Darougar S, Squires S. Sensitivity of immunoperoxidase and immunofluorescence staining for detecting chlamydia in conjunctival scrapings and in cell culture. J Clin Pathol 1978;31:1073-7.

${ }^{8}$ Woodland RM, Malam J, Darougar S. A rapid method for staining inclusions of chlamydia psittaci and chlamydia trachomatis. $J$ Clin Pathol 1982;35:642-4.

' Davies JA, Rees E, Hobson D, Karayiannis P. Isolation of chlamydia trachomatis from Bartholin's ducts. Br J Vener Dis
1978;54:409-13.

10 Johnson FWA, Hobson D. Factors affecting the sensitivity of replicating McCoy cells in the isolation and growth of chlamydia A (TRIC agents). J Hyg (Camb) 1976; 76:441-51.

"Schachter J, Dawson CR. Psittacosis-lymphogranuloma venereum agents/TRIC agents. In: Lennette EH, Schmidt NJ eds. Diagnostic procedures for viral, rickettsial and chlamydial infection. 5th ed. Washington DC: American Public Health Association, 1980:1021-59.

12 Croy TR, Kuo C-C, Wang S-p. Comparative susceptibility of eleven mammalian cell lines to infection with Trachoma Organisms. J Clin Microbiol 1975;1:434-9.

Requests for reprints to: Dr NRS Mohammed, Department of Medical Microbiology, University College Dublin, Dublin 4, Ireland. 